\title{
Observational Study of Peripheral Intravenous Catheter Outcomes in Adult Hospitalized Patients: A Multivariable Analysis of Peripheral Intravenous Catheter Failure
}

\author{
Nicole Marsh RN, BN, MadvPrac ${ }^{1,2,3 *}$, Joan Webster, RN, BA ${ }^{1,2,4}$, Emily Larsen, RN, BN, GDipHlthRes'1,2, \\ Marie Cooke, RN, PhD2,3, Gabor Mihala, MEng (Mech), GCert (Biostat)2,3,5,6, Claire M. Rickard, RN, PhD 1,2,3
}

\begin{abstract}
${ }^{1}$ Nursing \& Midwifery Research Centre, Royal Brisbane and Women's Hospital, Brisbane, Queensland, Australia; ${ }^{2}$ School of Nursing and Midwifery, Griffith University, Brisbane, Queensland, Australia; ${ }^{3}$ Alliance for Vascular Access Teaching and Research Group, Menzies Health Institute, Brisbane, Queensland, Australia; ${ }^{4}$ School of Nursing, Queensland University of Technology, Brisbane, Queensland, Australia; ${ }^{5}$ School of Medicine, Griffith University, Brisbane, Queensland, Australia; ${ }^{6}$ Centre for Applied Health Economics, Menzies Health Institute, Brisbane, Queensland, Australia.
\end{abstract}

BACKGROUND: Almost 70\% of hospitalized patients require a peripheral intravenous catheter (PIV), yet up to $69 \%$ of PIVs fail prior to completion of therapy.

OBJECTIVE: To identify risk factors associated with PIV failure.

DESIGN: A single center, prospective, cohort study.

SETTING: Medical and surgical wards of a tertiary hospital located in Queensland, Australia.

PARTICIPANTS: Adult patients requiring a PIV.

MEASUREMENTS: Demographic, clinical, and potential PIV risk factors were collected. Failure occurred if the catheter had complications at removal.

RESULTS: We recruited 1000 patients. Catheter failure occurred in 512 (32\%) of 1578 PIVs. Occlusion/infiltration risk factors included intravenous (IV) flucloxacillin (hazard ratio [HR], 1.98; 95\% confidence interval [Cl], 1.19-3.31), 22-gauge PIVs (HR, 1.43; 95\% Cl, 1.02-2.00), and female patients (HR, 1.48; 95\% Cl, 1.10-2.00). Phlebitis was associated with female patients $(\mathrm{HR}, 1.81 ; 95 \% \mathrm{Cl}, 1.40$ 2.35), bruised insertion sites (HR, 2.16; $95 \% \mathrm{Cl}, 1.26-3.71)$, IV flucloxacillin ( $\mathrm{HR}, 2.01 ; 95 \% \mathrm{Cl}, 1.26-3.21)$, and dominant side insertion (HR, 1.39; 95\% Cl, 1.09-1.77). Dislodgement risks were a paramedic insertion (HR, 1.78; $95 \% \mathrm{Cl}, 1.03$ 3.06). Each increase by 1 in the average number of daily PIV accesses was associated (HR 1.11, 95\% Cl 1.03-1.20)-(HR $1.14,95 \% \mathrm{Cl} 1.08-1.21$ ) with occlusion/infiltration, phlebitis and dislodgement. Additional securement products were associated with less (HR $0.32,95 \% \mathrm{Cl} 0.22-0.46)$-(HR 0.63, $95 \% \mathrm{Cl} 0.48-0.82$ ) occlusion/infiltration, phlebitis and dislodgement.

CONCLUSION: Modifiable risk factors should inform education and inserter skill development to reduce the currently high rate of PIV failure. Journal of Hospital Medicine 2018;13:83-89. Published online first October 18, 2017. (C) 2018 Society of Hospital Medicine eripheral intravenous catheter (PIV) insertion is the fastest, simplest, and most cost-effective method to gain vascular access, and it is used for short-term intravenous (IV) fluids, medications, blood products, and contrast media. ${ }^{1}$ It is the most common invasive device in hospitalized patients, ${ }^{2}$ with up to $70 \%$ of hospital patients receiving a PIV. ${ }^{3}$ Unacceptable PIV failure rates have been reported as high as $69 \% .^{4-7}$ Failure is most frequently due to phlebitis (vein wall irritation/inflammation), occlusion (blockage), infiltration or extravasation (IV fluids/vesicant therapy entering surrounding tissue), partial dislodgement or accidental removal, leakage,

\footnotetext{
*Address for correspondence and reprint requests: Nicole Marsh, RN, BN, MadvPrac, Center for Clinical Nursing, Royal Brisbane and Women's Hospital, Butterfield St, Herston, Queensland, 4029 Australia; Telephone: +61-3646-8740; Fax: +61-3646-5832; E-mail: nicole.marsh@health.qld.gov.au
}

Received: April 25, 2017; Revised: June 18, 2017

Accepted: June 21, 2017

2018 Society of Hospital Medicine DOI 10.12788/jhm.2867 and infection. ${ }^{4,6,8}$ These failures have important implications for patients, who endure the discomfort of PIV complications and catheter replacements, and healthcare staff and budgets.

To reduce the incidence of catheter failure and avoid preventable PIV replacements, a clear understanding of why catheters fail is required. Previous research has identified that catheter gauge, ${ }^{9-11}$ insertion site, ${ }^{12-14}$ and inserter skill10,15 have an impact on PIV failure. Limitations of existing research are small study sizes, ${ }^{16-18}$ retrospective design, ${ }^{19}$ or secondary analysis of an existing data set; all potentially introduce sampling bias. ${ }^{10,20}$

To overcome these potential biases, we developed a data collection instrument based on the catheter-associated risk factors described in the literature, ${ }^{9-11,13}$ and other potential insertion and maintenance risks for PIV failure (eg, multiple insertion attempts, medications administered), with data collected prospectively. The study aim was to improve patient outcomes by identifying PIV insertion and maintenance risk factors amenable to modification through education or alternative clinical interventions, such as catheter gauge selection or insertion site. 


\section{METHODS}

\section{Study Design and Participants}

We conducted this prospective cohort study in a large tertiary hospital in Queensland, Australia. Ethics committee approval was obtained from the hospital (HREC/14/ORBW/76) and Griffith University (NRS/26/14/HREC). The study was registered with the Australian New Zealand Clinical Trials Registry (ACTRN12615000738527). Patients in medical and surgical wards were screened Monday, Wednesday, and Friday between October 2014 and December 2015. Patients over 18 years with a PIV (BD Insyte ${ }^{\mathrm{TM}}$ Autoguard ${ }^{\mathrm{TM}}$ BC; Becton Dickinson, Franklin Lakes, NJ) inserted within 24 hours, and who were able to provide written informed consent, were eligible and recruited sequentially. Patients classified as palliative by the treating clinical team were excluded.

\section{Sample Size Calculation}

The "10 events per variable" rule was used to determine the sample size required to study 50 potential risk factors. ${ }^{21,22}$ This determined that 1000 patients, with an average of 1.5 PIVs each and an expected PIV failure of 30\% (500 events), were required.

\section{Data Collection}

At recruitment, baseline patient information was collected by a research nurse (ReNs) (demographics, admitting diagnosis, comorbidities, skin type, ${ }^{23}$ and vein condition) and entered into an electronic data platform supported by Research Electronic Data Capture (REDCap). ${ }^{24}$ Baseline data also included catheter variables (eg, gauge, insertion site, catheterized vein) and insertion details (eg, department of insertion, inserting clinician, number of insertion attempts). We included every PIV the participant had during their admission until hospital discharge or insertion of a central venous access device. PIV sites were reviewed Monday, Wednesday, and Friday by ReNs for site complications (eg, redness, pain, swelling, palpable cord). Potential risk factors for failure were also recorded (eg, infusates and additives, antibiotic type and dosage, flushing regimen, number of times the PIV was accessed each day for administration of IV medications or fluids, dressing type and condition, securement method for the catheter and tubing, presence of extension tubing or 3-way taps, patient mobility status, and delirium). A project manager trained and supervised ReNs for protocol compliance and audited study data quality. We considered PIV failure to have occurred if the catheter had complications at removal identified by the ReNs assessment, from medical charts, or by speaking to the patient and beside nurse. We grouped the failures in 1 of 3 types: (1) occlusion or infiltration, defined as blockage, IV fluids moving into surrounding tissue, induration, or swelling greater than $1 \mathrm{~cm}$ from the insertion site at or within 24 hours of removal; (2) phlebitis, defined as per clinicians' definitions or one or more of the following signs and symptoms: pain or tenderness scored at 2 or more on a 1 to 10 increasing severity pain scale, or redness or a palpable cord (either ex- tending greater than $1 \mathrm{~cm}$ from the insertion site) at or within 24 hours of PIV removal; and (3) dislodgement (partial or complete). If multiple complications were present, all were recorded.

\section{Statistical Analysis}

Data were downloaded from REDcap to Stata 14.2 (StataCorp., College Station, TX) for data management and analysis. Missing data were not imputed. Nominal data observations were collapsed into a single observation per device. Patient and device variables were described as frequencies and proportions, means and standard deviations, or medians and interquartile ranges. Failure incidence rates were calculated, and a Kaplan-Meier survival curve was plotted. In general, Cox proportional hazards models were fitted (Efron method) to handle tied failures (clustering by patient). Variables significant at $P<0.20$ on univariable analyses were subjected to multivariable regression. Generally, the largest category was set as referent. Correlations between variables were checked (Spearman's rank for binary variables, $\mathrm{R}$-squared value of linear regressions for continuous/categorical or continuous/continuous variables). Correlations were considered significant if $r>0.5$ and the lower bound of the $95 \%$ confidence interval $(\mathrm{Cl})$ was $>0.5$ (where calculated). Covariate interactions were explored, and effects at $P<0.05$ noted. The 4 steps of multivariable model building were (1) baseline covariates only with manual stepwise removal of covariates at $P \geq 0.05$, (2) treatment covariates only with manual stepwise removal of covariates at $P \geq 0.05$, (3) a combination of the derived models from (1) and (2) and manual stepwise removal of covariates at $P \geq 0.05$, and (4) manual stepwise addition and removal (at $P \geq 0.05$ ) of variables dropped during the previous steps and interaction testing. Final models were checked as follows: global proportional-hazards assumption test, concordance probability (that predictions and outcomes were in agreement), and Nelson-Aalen cumulative hazard function plotted against the Cox-Snell residuals.

\section{RESULTS}

Patient Characteristics

In total, 1000 patients with 1578 PIVs were recruited. The average age was 54 years and the majority were surgical patients (673; 67\%). Almost half of patients $(455 ; 46 \%)$ had 2 or more comorbidities, and 334 (33\%) were obese (body mass index greater than 30). Sample characteristics are shown by the type of catheter failure in Table 1.

\section{Peripheral Intravenous Catheter Characteristics}

All 1578 PIVs were followed until removal, with only 7 PIVs (0.44\%) having missing data for the 3 outcomes of interest (these were coded as nonfailures for analysis). Sixty percent of participants had more than 1 PIV followed in the study. Doctors and physicians inserted 1278 (83\%) catheters. A total of 550 (35\%) were placed in the ward, with 428 (28\%) inserted in the emergency department or ambulance. A third of the catheters $(540 ; 34 \%)$ were 18-gauge or larger in diameter, and 1000 (64\%) were located in the cubital fossa or hand. Multiple insertion attempts were required to place 315 (23\%) PIVs. No 
TABLE 1. Participant Characteristics at Recruitment by Failure Type

\begin{tabular}{|c|c|c|c|c|}
\hline \multirow{2}{*}{ Characteristic } & \multicolumn{4}{|c|}{ Complication Class } \\
\hline & Totala $^{\mathrm{a}}$ & Occlusion/Infiltration Type ${ }^{b}$ & Phlebitis Type $^{b}$ & Dislodgement Type ${ }^{b}$ \\
\hline Age $(y$, mean and SD) & $54(19)$ & $57(17)$ & $52(19)$ & $59(19)$ \\
\hline Sex (male) & $546(55)$ & $80(15)$ & $99(18)$ & $80(15)$ \\
\hline \multicolumn{5}{|l|}{ BMI (WHO IC) } \\
\hline normal or underweight (BMl <25) & $301(30)$ & $43(14)$ & $65(22)$ & $50(17)$ \\
\hline preobese $(25 \leq \mathrm{BMI}<30)$ & $358(36)$ & $66(18)$ & $71(20)$ & $45(13)$ \\
\hline obese class $\mathrm{I}(30 \leq \mathrm{BMI}<35)$ & $182(18)$ & $25(14)$ & $37(20)$ & $23(13)$ \\
\hline obese class II-III (BMI $\geq 35$ ) & $152(15)$ & $35(23)$ & $33(22)$ & $18(12)$ \\
\hline Skin type: whitec & $857(86)$ & $146(17)$ & $25(17)$ & $14(10)$ \\
\hline \multicolumn{5}{|l|}{ Comorbidities } \\
\hline none & $259(26)$ & $30(12)$ & $52(20)$ & $24(9)$ \\
\hline 1 & $286(29)$ & $49(17)$ & $66(23)$ & $34(12)$ \\
\hline 2 & $181(18)$ & $38(21)$ & $37(20)$ & $28(15)$ \\
\hline 3 & $136(14)$ & $26(19)$ & $26(19)$ & $25(18)$ \\
\hline 4 or more & $138(14)$ & $26(19)$ & $28(20)$ & $26(19)$ \\
\hline History of tobacco/nicotine use & $578(58)$ & $98(17)$ & $116(20)$ & $88(15)$ \\
\hline \multicolumn{5}{|l|}{ Reason for admission: } \\
\hline gastrointestinal surgery & $212(21)$ & $46(22)$ & $53(25)$ & $27(13)$ \\
\hline orthopedic surgery & $199(20)$ & $30(15)$ & $49(25)$ & $31(16)$ \\
\hline Infection (any type) & $107(11)$ & $34(32)$ & $43(40)$ & $17(16)$ \\
\hline Wound & $502(50)$ & $83(17)$ & $99(20)$ & $68(14)$ \\
\hline Drain or IDC & $266(27)$ & $49(18)$ & $53(20)$ & $38(14)$ \\
\hline No dietary/fluid restrictions & $631(63)$ & $121(19)$ & $147(23)$ & $101(16)$ \\
\hline
\end{tabular}

aColumn percentages shown, where applicable.

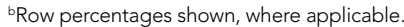

'Skin type 2 as per the Fitzpatrick scale.

${ }^{\mathrm{G} G o o d}$ (healthy, well hydrated, elastic), Fair (intact, mildly dehydrated - reduced elasticity), Poor (paper, dehydrated-small amount or no elasticity).

NOTE: $\mathrm{n}(\%)$ shown unless otherwise noted. Occlusion type $=$ occlusion or infiltration at removal, induration or swelling $(>1 \mathrm{~cm})$ at or within \pm 24 hours of removal; phlebitis type $=$ phlebitis or pain at removal, pain, tenderness, erythema or palpable cord $(>1 \mathrm{~cm})$ at or within \pm 24 hours of removal; dislodgement type = accidental removal or dislodgement at removal; proportions calculated using the number of non-missing values in the denominator; comorbidities were as per medical diagnosis documented in patient's medical chart. Abbreviations: BMI, body mass index IDC, indwelling catheter; SD, standard deviation; WHO IC, World Health Organization International Classification.

PIVs were inserted with ultrasound, as this is rarely used in this hospital. The flushing policy was for the administration of $9 \%$ sodium chloride every 8 hours if no IV medications or fluids were ordered. Table 2 contains further details of device-related characteristics. Although the hospital policy was for catheter removal by 72 hours, dwell time ranged from $<1$ to 14 days, with an average of 2.4 days.

\section{Peripheral Intravenous Catheter Complications}

Catheter failure (any cause) occurred in 512 (32\%) catheters, which is a failure rate of 136 per 1000 catheter days ( $95 \% \mathrm{Cl}, 125-148)$. A total of 346 patients out of 1000 (35\%) had at least 1 failed PIV during the study. Failures were 267 phlebitis (17\%), 228 occlusion/ infiltration (14\%), and/or 154 dislodgement (10\%; Figure), with some PIVs exhibiting multiple concurrent complications (Table 2). 
TABLE 2. Peripheral Intravenous Catheter Characteristics at Insertion by Failure Type

\begin{tabular}{|c|c|c|c|c|}
\hline Characteristic & \multicolumn{4}{|c|}{ Complication Class } \\
\hline Group size & $1578(100)$ & $228(14)$ & $267(17)$ & $154(10)$ \\
\hline First device for patient & $1000(63)$ & $121(12)$ & $153(15)$ & $95(10)$ \\
\hline \multicolumn{5}{|l|}{ Inserted by: } \\
\hline doctor & $1278(83)$ & $177(14)$ & $218(17)$ & $118(9)$ \\
\hline paramedic & $92(6)$ & $14(15)$ & $11(12)$ & $16(17)$ \\
\hline \multicolumn{5}{|l|}{ Inserted at: } \\
\hline ward & $550(35)$ & $106(19)$ & $113(21)$ & $61(11)$ \\
\hline operating theater & $481(30)$ & $42(9)$ & $57(12)$ & 31 (6) \\
\hline emergency department & $340(22)$ & $51(15)$ & $67(20)$ & $33(10)$ \\
\hline ambulant care & $88(6)$ & $14(16)$ & $10(11)$ & $16(18)$ \\
\hline 18 & $346(23)$ & $40(12)$ & $58(17)$ & $27(8)$ \\
\hline 20 & $733(49)$ & $104(14)$ & $127(17)$ & $61(8)$ \\
\hline 22 & $217(15)$ & $50(23)$ & $43(20)$ & $32(15)$ \\
\hline Location: & & & & $59(10)$ \\
\hline hand & $582(37)$ & $85(15)$ & $84(14)$ & $41(10)$ \\
\hline cubital fossa & $418(27)$ & $61(15)$ & $75(20)$ & $23(9)$ \\
\hline lower forearm & $264(17)$ & $38(14)$ & $44(17)$ & $21(11)$ \\
\hline wrist & $190(12)$ & $21(11)$ & $35(18)$ & $8(8)$ \\
\hline upper forearm & $106(7)$ & $22(21)$ & $27(25)$ & \\
\hline Inserted on dominant side & $738(47)$ & $114(15)$ & $151(20)$ & $76(10)$ \\
\hline simple transparent dressing & $592(38)$ & $71(12)$ & $87(15)$ & $48(8)$ \\
\hline adhesive gauze dressing & $134(9)$ & $13(10)$ & $17(13)$ & $8(6)$ \\
\hline other & $97(6)$ & $12(12)$ & $19(20)$ & $11(11)$ \\
\hline
\end{tabular}

${ }^{a}$ Column percentages shown, where applicable.

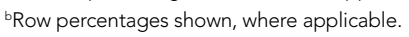

Including multiple insertion attempts.

Mean and standard deviation.

NOTE: $\mathrm{n}(\%)$ shown unless otherwise noted; occlusion type = occlusion or infiltration at removal, induration, or swelling $(>1 \mathrm{~cm})$ at or within \pm 24 hours of removal; phlebitis type $=$ phlebitis or pain at removal, pain, tenderness, erythema, or palpable cord $(>1 \mathrm{~cm})$ at or within \pm 24 hours of removal; dislodgement type $=$ accidental removal or dislodgement at removal; proportions calculated by using the number of nonmissing values in the denominator.

\section{Multivariable Analysis \\ Occlusion/Infiltration}

The multivariable analysis (Table 3) showed occlusion or infiltration was statistically significantly associated with female patients (hazard ratio $[\mathrm{HR}], 1.48 ; 95 \% \mathrm{Cl}, 1.10-2.00$ ), with a 22-gauge catheter (HR, 1.43; $95 \% \mathrm{Cl}, 1.02-2.00)$, IV flucloxacillin $(\mathrm{HR}, 1.98 ; 95 \% \mathrm{Cl}, 1.19-3.31)$, and with frequent PIV access (HR, $1.12 ; 95 \% \mathrm{Cl}, 1.04-1.21$; ie, with each increase of 1 in the mean medications/fluids administrations per day, relative PIV failure increased 112\%). Less occlusion and infiltration were statistical- ly significantly associated with securement by using additional nonsterile tape ( $\mathrm{HR}, 0.46 ; 95 \% \mathrm{Cl}, 0.33-0.63)$, elasticized tubular bandages ( $\mathrm{HR}, 0.49 ; 95 \% \mathrm{Cl}, 0.35-0.70)$, or other types of additional securement for the PIV ( $\mathrm{HR}, 0.35 ; 95 \% \mathrm{Cl}, 0.26-0.47)$.

\section{Phlebitis}

Phlebitis was statistically significantly associated with female patients (HR, 1.81; 95\% Cl, 1.40-2.35), bruising at the insertion site ( $\mathrm{HR}, 2.16 ; 95 \% \mathrm{Cl}, 1.26-3.71)$, insertion in patients' dominant side (HR, 1.39; 95\% Cl, 1.09-1.77), IV flucloxicillin (HR, 2.01; 


\begin{tabular}{|c|c|c|c|}
\hline \multirow[b]{2}{*}{ Predictors } & \multicolumn{3}{|c|}{ Hazard Ratios $(95 \% \mathrm{Cl})$ by Complication Class } \\
\hline & $\begin{array}{l}\text { Occlusion/Infiltration Type } \\
\qquad n=1488\end{array}$ & $\begin{array}{l}\text { Phlebitis Type } \\
n=1565\end{array}$ & $\begin{array}{l}\text { Dislodgement Type } \\
\quad n=1533\end{array}$ \\
\hline Age (1 y increase) & $\wedge$ & $0.99(0.98-0.99)^{\mathrm{a}}$ & $\wedge$ \\
\hline Female gender & $1.48(1.10-2.00)^{b}$ & $1.81(1.40-2.35)^{\mathrm{a}}$ & $\wedge$ \\
\hline Inserted by paramedic (ref. doctor or nurse) & $\wedge$ & $\wedge$ & $1.78(1.03-3.06) b$ \\
\hline 22-gauge device & $1.43(1.02-2.00)^{b}$ & $\wedge$ & $\wedge$ \\
\hline Inserted on dominant side & $\wedge$ & $1.39(1.09-1.77)^{b}$ & $\wedge$ \\
\hline Bruising due to insertion & $\wedge$ & $2.16(1.26-3.71)^{b}$ & $\wedge$ \\
\hline Nonsterile tape applied (ever) & $0.46(0.33-0.63)^{a}$ & $0.63(0.48-0.82)^{b}$ & $0.44(0.31-0.63) a$ \\
\hline Elasticized tubular bandage applied (ever) & $0.49(0.35-0.70)^{\mathrm{a}}$ & $\wedge$ & $\wedge$ \\
\hline Other securement applied (ever) & $0.35(0.26-0.47)^{a}$ & $0.53(0.39-0.70)^{\mathrm{a}}$ & $0.32(0.22-0.46) a$ \\
\hline Number of accesses (mean per day) & $1.12(1.04-1.21)^{b}$ & $1.14(1.08-1.21)^{\mathrm{a}}$ & $1.11(1.03-1.20) b$ \\
\hline \multicolumn{4}{|c|}{ Medications administered (at any time during trial): } \\
\hline IV cephazolin & $\wedge$ & $0.63(0.44-0.89)^{b}$ & $\wedge$ \\
\hline IV flucloxacillin & $1.98(1.19-3.31)^{b}$ & $2.01(1.26-3.21)^{b}$ & $\wedge$ \\
\hline \multicolumn{4}{|l|}{$\mathrm{a} P<.001}$. \\
\hline \multicolumn{4}{|l|}{${ }^{\mathrm{b}} \mathrm{P}<.05$} \\
\hline \multicolumn{4}{|c|}{$\begin{array}{l}\text { NOTE: Occlusion type }=\text { occlusion or infiltration at removal, induration, or swelling }(>1 \mathrm{~cm}) \text { at or within } \pm 24 \text { hours of removal; phlebitis type }=\text { phlebitis or pain at removal, pain, tenderness, } \\
\text { erythema, or palpable cord }(>1 \mathrm{~cm}) \text { at or within } \pm 24 \text { hours of removal; dislodgement type }=\text { accidental removal or dislodgement at removal; } \wedge \text { not part of the multivariable model as the results } \\
\text { did not reach significance. Abbreviations: } \mathrm{Cl} \text {, confidence interval; IV, intravenous; meds, medications; ref., referent category. }\end{array}$} \\
\hline
\end{tabular}

$95 \% \mathrm{Cl}, 1.26-3.21)$, or with frequent PIV access (HR, 1.14; $95 \%$ $\mathrm{Cl}, 1.08-1.21)$. Older age, (HR, 0.99; 95\% Cl, 0.98-0.99; ie, each year older was associated with $1 \%$ less phlebitis), securement with additional nonsterile tape $(\mathrm{HR}, 0.63 ; 95 \% \mathrm{Cl}, 0.48-0.82)$ or with any other additional securement $(\mathrm{HR}, 0.53$; $95 \% \mathrm{Cl}, 0.39$ $0.70)$, or the administration of IV cephazolin ( $\mathrm{HR}, 0.63 ; 95 \% \mathrm{Cl}$, 0.44-0.89) were associated with lower phlebitis risk.

\section{Dislodgement}

Statistically significant predictors associated with an increased risk of PIV dislodgement included paramedic insertion (HR, 1.78; 95\% Cl, 1.03-3.06) and frequent PIV access (HR, 1.11; 95\% $\mathrm{Cl}, 1.03-1.20)$. A decreased risk was associated with the additional securement of the PIV, including nonsterile tape $(H R$, $0.44 ; 95 \% \mathrm{Cl}, 0.31-0.63)$ or other forms of additional securement (HR, 0.32; 95\% Cl, 0.22-0.46).

\section{DISCUSSION}

One in 3 PIVs failed in this study, with phlebitis as the most common cause of PIV failure. The $17 \%$ phlebitis rate reflected clinician-reported phlebitis or phlebitis observed by research staff using a 1-criteria definition because any sign or symptom can trigger PIV removal (eg, pain), even if other signs or symptoms are not present. Reported phlebitis rates are lower if definitions require 2 signs or symptoms. ${ }^{4,6}$ With over 71 different phlebitis assessment scales in use, and none well validated, the best method for diagnosing phlebitis re- mains unclear and explains the variation in reported rates. ${ }^{25}$ Occlusion/infiltration and dislodgement were also highly prevalent forms of PIV failure at $14 \%$ and $10 \%$, respectively. Occlusion and infiltration were combined because clinical staff use these terms interchangeably, and differential diagnostic tools are not used in practice. Both result in the same outcome (therapy interruption and PIV removal), and this combination of outcomes has been used previously. ${ }^{23}$ No PIV-associated bloodstream infections occurred, despite the

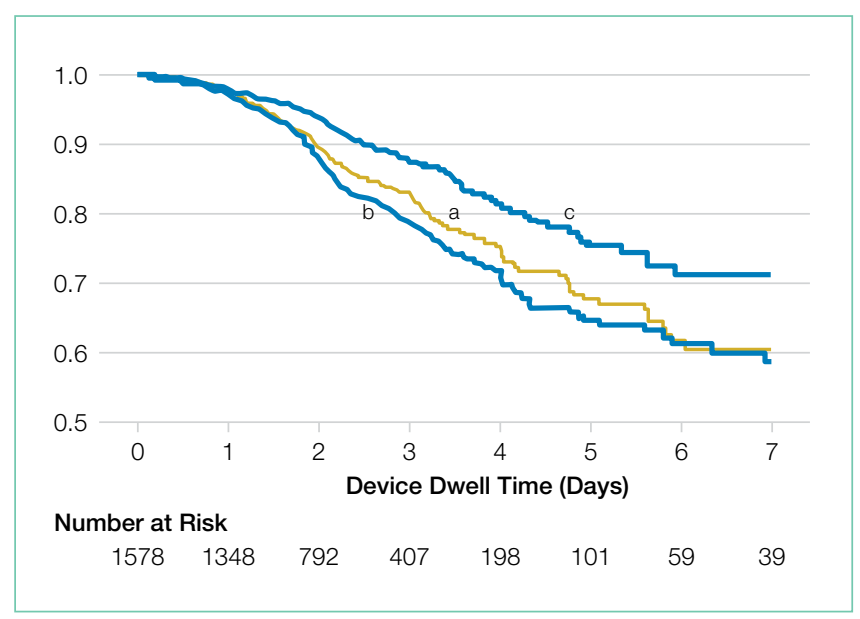

FIG. Kaplan-Meier curve of (a) occlusion or infiltration at removal, (b) phlebitis or pain at removal, and (c) accidental removal or dislodgement. 
heightened awareness of these infections in the literature. ${ }^{3}$

Females had significantly more occlusion/infiltration and phlebitis than males, in keeping with previous studies. 7,9,10 This could be because of females' smaller vein caliber, although the effect remained after adjustment for PIV gauge.,26 The effect of aging on vascular endothelium and structural integrity may explain the observed decrease in phlebitis of $1 \%$ with each older year of age. ${ }^{27}$ However, gender and age effects could be explained by psychosocial factors (eg, older people may be less likely to admit pain, or we may question them less sympathetically), but, regardless, women and younger patients should be monitored more closely.

We found 22-gauge catheters were more likely to fail from occlusion/infiltration than other sizes. This confirms similar findings from Abolfotouh et al. ${ }^{9}$ PIV gauge selection for this study was made at the inserter's discretion and may be confounded by smaller vein size, which was not measured. In addition, risk may be because of smaller gauge alone or also more influenced by the shorter length of the studied 22-gauge $(25 \mathrm{~mm}$ ) than the $<20$-gauge catheters $(30 \mathrm{~mm})$. These results question international guidelines, which currently recommend the smallest gauge peripheral catheter possible, ${ }^{28,29}$ and randomized trials are needed. Although practice varies between inserters, some preferentially cannulate the nondominant limb. We are not aware of previous studies on this practice; however, our results support this approach.

Flucloxacillin was associated with a 2 -fold increase in occlusion/infiltration and phlebitis. Although multiple studies have reported IV medications ${ }^{9,11}$ and IV antibiotics ${ }^{10,30,31}$ as risk factors for PIV failure, none have identified flucloxacillin as an independent risk factor. IV flucloxacillin is recommended for reconstitution as $1 \mathrm{~g}$ in $15 \mathrm{~mL}$ to $20 \mathrm{~mL}$ of sterile water, and injection over 3 to 4 minutes, although this may not be adhered to in practice. Alternative administration regimes or improved adherence to current policy may be needed. An exception to the relationship between IV antibiotics and catheter failure was IV cephazolin, associated with $40 \%$ relatively less phlebitis. This may be a spurious finding because the administration, $\mathrm{pH}$, and osmolality of cephazolin are similar to other IV antibiotics.

The more PIVs that were accessed per day, whether for infusions or medications, the more failure occurred from occlusion/ infiltration, phlebitis, and dislodgement. This suggests that peripheral veins are easily damaged and/or inflamed by the influx of fluids or medications. Lower injection pressures or the timely transfer to oral medications may limit this problem. Flushing regimens may also assist because practice varies greatly, and questions on whether slow continuous flush infusion or intermittent manual flushing are more vein-protective, and the optimal flush volume, frequency, and technique (eg, pulsatile) remain. ${ }^{32,33}$ Manual handling for frequent access may loosen dressings and securement, thus explaining the observed association between frequent access and catheter dislodgement. Finally, the association between use and failure may indicate that many of these patients were not suitable for a PIV, and different approaches (eg, ultrasound-guided insertion) or a midline may have been a superior option. There is growing emphasis on the need for better preinsertion assessment and selection of the most appropriate device for the patient and the IV treatment required. ${ }^{34}$

Suboptimal dressings or securements are not unusual in hospitals. ${ }^{35}$ Despite our policy of PIV securement with bordered transparent dressings, we found 4 dressing types in use. In addition, we found almost $50 \%$ of PIVs had an additional (secondary) securement, and this was associated with significantly less PIV failure of all 3 types. This suggests that 1 or more of nonsterile tape, elasticized tubular bandages, or other securement (eg, bandage or second transparent dressing) can reduce PIV failure, although a randomized trial is lacking. ${ }^{36}$ Whether the dressing was failing and required reinforcement or hospital staff lacked confidence in the dressing and placed additional securement preventatively is unclear. Both PIV failure and PIV dressing failure are common, and further research into superior PIV products and practices is urgently needed. Paramedic insertions had a higher risk of dislodgement, suggesting that the increased emphasis on securement should start in the prehospital setting.

While multiple or difficult insertion attempts were not associated with PIV failure, insertions were not directly observed, and clinicians may have underreported attempts. In contrast, insertion-related bruising (a surrogate for difficult insertion) was associated with more than double the incidence of phlebitis. The long-term implications of multiple insertion attempts on patient's vasculature are unclear, but we believe first time PIV insertion is important to patients and of interest to clinicians. A recent systematic review of strategies associated with first attempt PIV insertion success in an emergency department found little evidence for effective strategies and recommended further research. ${ }^{37}$

The overall PIV failure rate in our study was $32 \%$, lower than the $35 \%$ to $40 \%$ failure observed in our previous randomized controlled trials, which had more stringent inclusion and exclusion criteria (eg, longer predicted duration of therapy). 6,38 The implications for patients and costs to the organization of frequent catheter replacement demonstrate urgent need for further research in this area of practice. ${ }^{39}$ A strength of this study is that all PIVs, regardless of the expected length of dwell time or reason for insertion, were eligible for inclusion, providing more generalizable results. The PIV failure rate of $32 \%$ is concerning because these failures trigger treatment delays and replacement insertions, with significant increased labor and equipment costs. The mean cost of PIV replacement has been costed at AUD $\$ 69.30$ or US \$51.92 (as per 2010 \$ value) per episode of IV treatment. ${ }^{40}$ For our hospital, which uses 200,000 PIVs per year, the current level of PIV failure suggests almost AU \$5.5 (US \$4.1) million in waste annually at this site alone.

The additional strengths of this study include the extensive information collected prospectively about PIV insertion and maintenance, including information on who inserted the PIV, IV medications administered, and PIV dressings used. Limitations were the population of surgical and medical patients in 1 tertiary hospital, which may not be generalizable to other settings. 


\section{CONCLUSION}

Our study confirms the high rate of catheter failure in acute care hospitals, validates existing evidence related to PIV failure, and identifies new, potentially modifiable risk factors to improve PIV insertion and management. Implications for future research were also identified.

\section{Acknowledgments}

The researchers acknowledge and thank the nurses and patients involved in this study. The authors would also like to acknowledge Becton Dickinson for partly funding this study in the form of an unrestricted grant-in-aid paid to Griffith University. Becton Dickinson did not design the study protocol, collect or analyze data, and did not prepare or review the manuscript.

\section{References}

1. Sabri A, Szalas J, Holmes KS, Labib L, Mussivand T. Failed attempts and improvement strategies in peripheral intravenous catheterization. Biomed Mater Eng. 2012;23(1-2):93-108

2. Webster J, Osborne S, Rickard CM, New K. Clinically-indicated replacement versus routine replacement of peripheral venous catheters. Cochrane $\mathrm{Li}$ brary. 2015;8:CD007798. 3. Zingg W, Pittet D. Peripheral venous catheters: an under-evaluated problem. Int J Antimicrob Agents. 2009;34 Supp 4:S38-S42.

4. Webster J, Clarke S, Paterson D, et al. Routine care of peripheral intravenous catheters versus clinically indicated replacement: randomised controlled trial. BMJ. 2008;337:157-160.

5. Bausone-Gazda D, Lefaiver CA, Walters SA. A randomized controlled trial to compare the complications of 2 peripheral intravenous catheter-stabilization systems. J Infus Nurs. 2010;33(6):371-384.

6. Rickard CM, Webster J, Wallis MC, et al. Routine versus clinically indicated replacement of peripheral intravenous catheters: a randomised controlled equivalence trial. Lancet. 2012;380(9847):1066-1074

7. Dillon MF, Curran J, Martos R, et al. Factors that affect longevity of intravenous cannulas: a prospective study. Q J Med. 2008;101(9):731-735.

8. Bolton D. Improving peripheral cannulation practice at an $\mathrm{NHS}$ Trust. $\mathrm{Br}$ Nurs. 2010;19(21):1346, 1348-1350.

9. Abolfotouh MA, Salam M, Bani-Mustafa A, White D, Balkhy HH. Prospective study of incidence and predictors of peripheral intravenous catheter-induced complications. Ther Clin Risk Manag. 2014;10:993-1001.

10. Wallis MC, McGrail M, Webster J, et al. Risk factors for peripheral intravenous catheter failure: a multivariate analysis of data from a randomized controlled trial. Infect Control Hosp Epidemiol. 2014;35(1):63-68.

11. Catney MR, Hillis S, Wakefield B, et al. Relationship between peripheral intravenous catheter Dwell time and the development of phlebitis and infiltration. J Infus Nurs. 2001;24(5):332-341.

12. Barbut F, Pistone $T$, Guiguet $M$, et al. Complications due to peripheral venous catheterization. Prospective study. La Presse Medicale. 2003;32(10):450-456.

13. Cicolini G, Bonghi AP, Di Labio L, Di Mascio R. Position of peripheral venous cannulae and the incidence of thrombophlebitis: an observational study. J Adv Nurs. 2009;65(6):1268-1273.

14. Saini R, Agnihotri M, Gupta A, Walia I. Epidemiology of infiltration and phlebitis. Nursing and Midwifery Research Journal. 2011;7:22-33.

15. Palefski SS, Stoddard GJ. The infusion nurse and patient complication rates of peripheral-short catheters: a prospective evaluation. J Intraven Nurs. 2001;24(2):113-123.

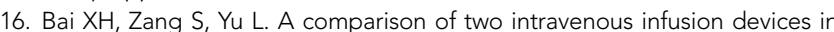
lung carcinoma patients receiving combined radiotherapy and chemotherapy. J Cancer Res Ther. 2013;9(4):664-667.

17. Goransson KE, Johansson E. Prehospital peripheral venous catheters: a prospective study of patient complications. J Vasc Access. 2012;13(1):16-21.

18. Karadeniz G, Kutlu N, Tatlisumak E, Ozbakkaloglu B. Nurses' knowledge regarding patients with intravenous catheters and phlebitis interventions. J Vasc Nurs. 2003;21(2):44-47.

19. Fields JM, Dean AJ, Todman RW, et al. The effect of vessel depth, diameter, and location on ultrasound-guided peripheral intravenous catheter longevity. Am J Emerg Med. 2012;30(7):1134-1140.

20. McNeill EE, Hines NL, Phariss R. A clinical trial of a new all-in-one peripheral-short catheter. J Assoc Vasc Access. 2009;14(1):46-51.

21. Vittinghoff $E, M c C u l l o c h ~ C E$. Relaxing the rule of ten events per variable in
Disclosure: On behalf of NM and CMR, Griffith University has received unrestricted educational and research grants and consultancy payment for lectures from $3 \mathrm{M}$ and Becton Dickinson. On behalf of NM, MC, and CMR, Griffith University has received unrestricted investigator-initiated research grants from Centurion Medical Products and Entrotech Lifesciences (manufacturers of PIV dressings) and Becton Dickinson (manufacturer of PIVs). On behalf of MC, Griffith University has received a consultancy payment to develop education material from Baxter. On behalf of CMR, Griffith University has received unrestricted donations or investigator initiated research grants unrelated to this research from Adhezion, Angiodynamics, Baxter, Carefusion, Cook Medical, Hospira, Mayo, Smiths Medical, and Vygon. On behalf of CMR, Griffith University has received consultancy payments for educational lectures or professional opinion from B. Braun, Bard, Carefusion, Mayo, ResQDevices, and Smiths Medical. On behalf of EL, Griffith University has received consultancy payments for educational lecture from $3 \mathrm{M}$. On behalf of MC, Griffith University has received a consultancy payment to develop education material from Baxter. As this was an observational study, no products were trialed in this study. JW and GM have no conflicts of interest.

logistic and Cox regression. Am J Epidemiol. 2007;165(6):710-718.

22. Mallett S, Royston P, Dutton S, Waters R, Altman DG. Reporting methods in studies developing prognostic models in cancer: a review. BMC Med. 2010;8(1):20

23. Fitzpatrick TB. The validity and practicality of sun-reactive skin types I through VI. Arch Dermatol. 1988;124(6):869-871.

24. Harris PA, Taylor R, Thielke R, Payne J, Gonzalez N, Conde JG. Research electronic data capture (REDCap)--a metadata-driven methodology and workflow process for providing translational research informatics support. J Biomed Inform. 2009:42(2):377-381.

25. Ray-Barruel G, Polit DF, Murfield JE, Rickard CM. Infusion phlebitis assessment measures: a systematic review. J Eval Clin Pract. 2014;20(2):191-202.

26. Jacobson AF, Winslow EH. Variables influencing intravenous catheter insertion difficulty and failure: an analysis of 339 intravenous catheter insertions. Heart Lung. 2005;34(5):345-359.

27. Schelper R. The aging venous system. Journal of the Association for Vascular Access. 2003;8(3):8-10

28. Gorski L, Hadaway L, Hagle M, McGoldrick M, Orr M, Doellman D. Infusion therapy standards of practice. J Infus Nurs. 2016;39(suppl 1):S1-S159.

29. Intravenous Nursing New Zealand. Provisional infusion therapy standards of practice. www.ivnnz.co.nz2012. Accessed March 31, 2017.

30. do Rego Furtado LC. Maintenance of peripheral venous access and its impact on the development of phlebitis: a survey of 186 catheters in a general surgery department in Portugal. J Infus Nurs. 2011;34(6):382-390.

31. Gorski LA, Hagle ME, Bierman S. Intermittently delivered IV medication and $\mathrm{pH}$ : reevaluating the evidence. J Infus Nurs. 2015;38(1):27-46.

32. Keogh S, Flynn J, Marsh N, Mihala G, Davies K, Rickard C. Varied flushing frequency and volume to prevent peripheral intravenous catheter failure: a pilot, factorial randomised controlled trial in adult medical-surgical hospital patients. Trials. 2016;17(1):348

33. Schreiber $S$, Zanchi $C$, Ronfani $L$, et al. Normal saline flushes performed once daily maintain peripheral intravenous catheter patency: a randomised controlled trial. Arch Dis Child. 2015;100(7):700-703.

34. Chopra V, Flanders SA, Saint S, et al. The Michigan Appropriateness Guide for Intravenous Catheters (MAGIC): results from a multispecialty panel using the RAND/UCLA appropriateness method. Ann Intern Med. 2015;163(6 Suppl):S1-S40

35. New KA, Webster J, Marsh NM, Hewer B. Intravascular device use, management, documentation and complications: a point prevalence survey. Aust Health Rev. 2014;38(3):345-349.

36. Marsh N, Webster J, Mihala G, Rickard C. Devices and dressings to secure peripheral venous catheters to prevent complications. Cochrane Database Syst Rev. 2015(6):CD11070

37. Parker SI, Benzies KM, Hayden KA, Lang ES. Effectiveness of interventions for adult peripheral intravenous catheterization: A systematic review and meta-analysis of randomized controlled trials. Int Emerg Nurs. 2016;31:15-21.

38. Webster J, Lloyd S, Hopkins T, Osborne S, Yaxley M. Developing a Research base for Intravenous Peripheral cannula re-sites (DRIP trial). A randomised controlled trial of hospital in-patients. Int J Nurs Stud. 2007;44(5):664-671.

39. Helm RE, Klausner JD, Klemperer JD, Flint LM, Huang E. Accepted but unacceptable: peripheral IV catheter failure. J Infus Nurs. 2015;38(3):189-203.

40. Tuffaha HW, Rickard CM, Webster J, et al. Cost-effectiveness analysis of clinically indicated versus routine replacement of peripheral intravenous catheters. Appl Health Econ Health Policy. 2014;12(1):51-58. 